\title{
POSSIBLE IMPLICATIONS OF ACCESS' TO BENEFIT SHARING PROVISIONS OF THE CONVENTION ON BIOLOGICAL DIVERSITY TO MAN AND THE BIOSPHERE RESERVES
}

\author{
SANJIV DE SILVA \\ Senior Programme Officer, Environmental Law, IUCN, Sri Lanka \\ Proceedings of the South and Central Asian MAB Meeting of Experts on \\ Environmental Conservation, Management and Research, Hikkaduwa, Sri Lanka \\ 15-18 October 2002
}

\begin{abstract}
Summary: This article deals with the relationship between Man and the Biosphere Reserves and the Convention on Biological Diversity, especially with regard to the sustainable use of genetic resources and the fair and equitable sharing of benefits arising from such use. The content explores the question of whether the regulation of access to genetic resources may be used as a mechanism for supporting the Man and the Biosphere objectives.
\end{abstract}

\section{Introduction}

The Convention on Biological Diversity (CBD), in Article 1, sets out three overall objectives: the conservation of biodiversity, the sustainable use of biodiversity and the fair and equitable sharing of the benefits arising from such use. Although stated as distinct objectives, they represent three steps in a single strategy that seeks to address the overarching global issue with regard to biodiversity conservation: how to balance biodiversity conservation with economic development in the context of relatively finite resources. These objectives, and the underlying rationale that the accruing of benefits from the sustainable use of biodiversity is an important incentive for biodiversity conservation, closely reflect the objectives and conceptual basis of Man and the Biosphere (MAB) Reserves: biodiversity conservation, sustainable development and research and other activities that provide solutions to local, national and global issues. Whilst whether this outlook is desirable is a highly subjective issue, both instruments appear to recognize the influence of economic considerations at the global, national and local levels that appear to predominate over cultural, religious and ethical considerations that may have ensured greater diversity in the past.

This article explores how access to genetic resources and the fair and equitable sharing of benefits (ABS) arising from such access, as provided for under the CBD, could contribute to furthering the objectives of MAB Reserves. To this end, the basic components of an $\mathrm{ABS}$ regime as envisioned in the $\mathrm{CBD}$ are set out below, and this is followed by a consideration of some practical aspects that should be considered where $\mathrm{ABS}$ is to be linked to $\mathrm{MAB}$ Reserve objectives. 


\section{Components of an Access and Benefit Sharing Regime under the CBD}

The ABS regime outlined in the CBD is a mechanism to implement the utilityoriented philosophy referred to above. It reflects a belief that existed at the time the CBD was formed that significant commercial applications would arise through the application of emerging biotechnologies to the organic compounds that constitute organisms. The Convention thus seeks to take advantage of a newfound utility to biodiversity, and attempts to capture and channel some of the perceived benefits arising from such use into biodiversity rich countries from which genetic resources are obtained, as it was believed that such benefits would provide incentives for conserving the organisms in which such material is found.

The ABS framework outlined in the CBD is founded on the affirmation of the principle of national sovereignty over a country's natural resources, and this provides the basis for a government's right to regulate access to genetic resources found in its territory according to national law. ${ }^{1}$ A government's right to regulate access implies some form of system or process for regulating the collection and use of these resources, and the distribution of benefits arising from such use between the country from which the resources were obtained, and those who developed the resources into commercial products. Whilst these forms have taken various designs, the concepts of Prior Informed Consent (PIC) ${ }^{2}$ and Mutually Agreed Terms (MATs) ${ }^{3}$ are highlighted by the CBD as key features for facilitatating the exercise of national sovereignty and for ensuring that benefits are shared fairly and equitably.

Prior informed consent may be viewed as the central procedural device recommended by the CBD for enabling Parties to determine whether any request for access is in keeping with national conservation and development priorities before deciding whether access should be granted, and what conditions should apply where access is granted. This may be understood to mean that a request for access shall be considered only after full disclosure of relevant information such as the identity and other relevant details of those seeking access, the specific resources sought, their quantities and locations, reasons for access and envisaged uses, and potential risks to the environment. Based on the particular national context, PIC may also apply not only to the government agency responsible for access, but also be required from local communities and private individuals who may be in possession of or have rights over biodiversity or traditional knowledge related to its use.

PIC is also the basis from which mutually agreed terms can be developed by identifying the stakeholders and generating the necessary information. The phrase mutually agreed terms appears in Articles 15 (4), which states that "access, where

\footnotetext{
1 Article 15(1), CBD

${ }^{2}$ Article 15(5), CBD

${ }^{3}$ Article 15(4),
} 
granted, shall be on mutually agreed terms subject to the provisions of this Article". This term also appears in Articles 16 (3) and 19 (2), and as "mutual agreement" in Article 18 (5) creating an environment in which the providers of genetic resources are in a position to negotiate on a more equal basis with the users of those resources, and by specifying certain types of benefits that parties to access and benefit-sharing arrangements must include in their agreements. Inherent in the phrase mutually agreed terms is the expectation of a negotiation between the Party providing genetic resources and a potential user. This aspect of MATs points not only to the importance of defining particular elements or features that each agreement should contain but also to the direct and central relevance of the procedural aspects of the regime in implementing this term. Consequently, how a country implements PIC will have a significant bearing on how governments and other stakeholders are able to benefit from the concept of mutually agreed terms.

MATs will vary depending upon the nature of use intended, and the beneficiaries will also be determined by from whom PIC is required. Some national measures might distinguish between commercial and academic research, with each option having a bearing on the form of prior informed consent and the nature of benefit-sharing measures required. In other cases the state as well as specific communities or even individuals may be stakeholders between whom benefits may be distributed.

Benefits could be financial and in-kind in nature. The combination and degree will depend on the specifics of each agreement. Financial benefits are likely to arise at the point of access (access fee) and as royalties if and when a commercial product is developed, whereas in-kind benefits would mainly include capacity development training, access and transfer of technology, knowledge. The Convention refers to specific forms of benefits and their fair and equitable sharing in a number of provisions including: the participation of providers in the scientific research process; ${ }^{4}$ the sharing of research results and development, and benefits arising from the commercial or other utilisation of genetic resources; ${ }^{5}$ the access to and transfer of technology; ${ }^{6}$ effective participation in the research process by providers; ${ }^{7}$ and priority access to results and benefits derived from biotechnologies based on genetic resources provided. ${ }^{8}$ The CBD further recognises that access to and transfer of technology are vital requirements for reaching the Convention's objectives, ${ }^{9}$ and requires Parties to ensure that their national policies and legislation facilitate access to and the transfer of technology particularly applicable to genetic resources (including those protected by IPRs) to developing countries from which such

\footnotetext{
${ }^{4}$ Article 15(6)

5 Article 15(7)

${ }^{6}$ Article 16(3)

7 Article 19(1)

${ }^{8}$ Article 19(2)

${ }^{9}$ Art. 16(1)
} 
genetic resources are accessed, on mutually agreed terms. ${ }^{10}$ The different types of benefits may therefore be targeted at or apply to a range of stakeholders involved in the access and use of these resources, thereby, in theory, providing incentives for the conservation of biodiversity. The CBD does not however provide details on the manner in which benefits, and particularly financial benefits, should be distributed apart from stating that such distribution should be fair and equitable which are also left undefined. To whom the benefits go within the country is thus a decision for each country, and will need to be incorporated in an ABS mechanism. In some cases, benefits will accrue directly to local-level parties through agreements, and the national government might attach conditions to these benefits, requiring, for example, that a portion be returned to a national trust fund, or that the bulk of benefits serve development and conservation objectives, or that only institutions or communities, and not individuals, benefit directly. The process engendered by PIC provides an opportunity for engaging different stakeholders in benefit-sharing negotiations that result in an appropriate, mutual agreement.

Another central consideration is the scope of access. What exactly access refers to is not defined in the CBD, although common sense dictates that it would apply to acts such as the collection and exchange of biological organisms or material. With regard to scope, the Convention states that access is limited to genetic resources which is defined by Article 2 as "genetic material of actual or potential value", where genetic material is defined as "any material of plant, animal, microbial or other origin containing functional units of heredity". Although this definition appears to exclude substances such as biochemicals which are not limited to "functional units of heredity", countries have opted to include these substances in their national ABS regimes, as leaving them out would undermine the extent to which the Convention would be able to generate benefits as they have proven to be of value to numerous industries. Countries may also wish to further qualify the types of material by indicating specific species or groups of species (such as threatened species) to which access will or will not be given. The scope of access may also be defined in terms of the geographical area from which access may be allowed or not allowed, and the uses and users to which access may or may not be granted.

In terms of administration of an $\mathrm{ABS}$ mechanism, it is likely that the relevant authorities have tended to be cross-sectoral, representative bodies, usually housed in the government as some form of inter-ministerial or inter-agency committee, which includes the representation and participation of indigenous and local communities, the private sector, the research community, nongovernmental organisations, and other stakeholders. Governments can play a variety of roles in biodiversity prospecting relationships, and this will be manifested in the types of national authorities they design. For example, a government might be party to every commercial agreement, acting as middleman and broker for local institutions and

${ }^{10}$ Article 16 (3) 
groups, providing monitoring services to ensure that the law is enforced, but leaving individual institutions to draft agreements with commercial partners, and to define terms on a case basis.

\section{How can ABS Provisions be Applied in Reaching the Objectives of MAB Reserves?}

Whilst an ABS regime may be constructed in theory, the challenge lies in applying concepts such as access PIC, MAT, and fair and equitable benefit sharing to the specific political, social and economic context operating within each country. Some practical considerations that may affect the utility of $\mathrm{ABS}$ as a strategy for meeting MAB Reserve objectives may include the following:

\section{Limited control over unauthorised access}

The ability to ensure compliance on the part of seekers of genetic resources with the rules of a national ABS regime is a factor that is likely to affect most countries, though to varying extents. Illegal flows of biodiversity contrary to existing national laws that regulate their export occurs in most countries, and this is likely to remain a logistical challenge in spite of the adoption of a national regime to regulate access and benefit sharing. Species belonging to lower taxonomic groups are particularly vulnerable due to their small size (in general) and the number of methods available for concealing and smuggling samples (e.g. tubes, photographic film cases, books). Furthermore, in countries where economic development is seen as the priority, and foreign income earning activities such as export-oriented trade and tourism are encouraged, the political economy may not be conducive to introducing stringent monitoring and enforcement rules that may affect such trades. Where such requirements do exist, their effective implementation rests on the capacities and interest of the relevant enforcement agencies in charge of in-situ and ex-situ biodiversity and points of export. These qualities may in term be partially influenced by the degree to which an ABS regime is supported at the political level as this is likely to determine the level of investment in manpower, training and the provision of relevant infrastructure for the effective enforcement of rules.

Genetic material may also be exported through several legitimate activities that have no direct bioprospecting agenda. These may include the export of biodiversity as food or as ornaments, where the genetic material is carried along with the organisms or their parts. As the range of species subject to such trade expands, this will also act as a loophole with no obvious practical solution in the current global trade context. The regulation of such trades may be particularly difficult in view of the rules against restrictions on international trade imposed by the World Trade Organisation of which a large number of CBD parties are members. 


\section{Difficulty in determining meaningful values for benefit sharing}

There is also some uncertainty with regard to the value of returns from granting access. Experience with royalty agreements have so far failed to convince some observers that returns will be substantial. Not only are the percentages of profits paid as royalty low (between $3-5 \%$ ), it is also a fact that access may not result in any commercial products. The infrequency of actual applications and the low royalty percentages allocated to the source countries thus suggests that the impact of genetic resources as a stimulus for biodiversity conservation may not be great as expected as when the CBD was developed. Furthermore, even where products are developed, the time lag between access and the identification, development, testing approval and marketing of the products are also likely to be considerable (as much as $10-15$ years).

\section{Limited control over the issuance of Intellectual Property Rights (IPRs)}

Where genetic resources are used to develop a product in another country, the ability of the country that supplied the resources may find it difficult to either prevent the granting of a patent or enforce its right to a share of royalties whether or not a formal agreement between the provider and user exists. Even if an agreement that indicates the origin of the resources exists, the options for obtaining redress for breaches of contracts spanning more than one national jurisdiction are few. Although some patent applications have been successfully challenged in the recent past in the International Court of Justice, the costs involved in mobilising the expertise and information required to do this is likely to present serious obstacles to the use of this option on a frequent basis.

Another important factor that contributes to this situation is the failure on the part of the governments of countries in which users operate to incorporate rules in their national legal frameworks that require users to abide by the spirit and conditions of the CBD ${ }^{11}$ and the national laws of the country from which genetic resources are accessed.

\section{Weaknesses in international IPR laws for recognising and protecting traditional knowledge}

In view of the fact that access to traditional knowledge pertaining to genetic resources may also be sought in an access application, the international patent laws are likely to have a negative baring on the interests of the holders or sources of such knowledge.

\footnotetext{
${ }^{11}$ Article 15(7) of the CBD requires Contracting Parties to take "legislative, administrative or policy measures, as appropriate ... with the aim of sharing in a fair and equitable way the results of research and development and the benefits arising from the commercial and other utilization of genetic resources with the Contracting Party providing such resources".
} 
This is because the recognition of traditional knowledge and practices by these laws is limited to western notions of innovation and novelty, and hence do not recognise the informal innovations that characterize much of traditional knowledge and practices. Interpreted as such, such knowledge and practices do not satisfy the legal test of novelty, and the requirement that innovations be developed by distinct persons at a particular moment in time. The reason for this lies in that fact that most indigenous and local innovations, involve an accumulative, informal process continued over time, with modifications and adaptations that build upon existing knowledge by a succession of custodians. This type of innovation is therefore not defined by time as it is perpetually evolving or ongoing.

\section{How Should ABS or Any Research Agreement be Used for Promoting MAB Reserves Objectives?}

Ongoing debates over the implications of the CBD's access and benefit sharing provisions for national biodiversity conservation have given rise to varying interpretations of these provisions' utility, and a generally cautious approach to their implementation may be observed. This is not altogether surprising considering that these provisions constitute a novel approach to biodiversity conservation, the fact that countries providing the resources do not have complete control over enforcement of access agreements where these involve foreign parties, and the absence of practical experience in implementing an ABS regime.

The CBD also emerged in the midst of the debate over "biopiracy", and, although it addresses aspects of it (e.g. recognises of the right of countries to regulate access to genetic resources, sets out access principles), the expectation that an ABS framework will or can eradicate "biopiracy" is not realistic, and may be an unfair expectation of the CBD.

Instead, the function of an ABS framework may be to provide a clear framework of rules and procedure for those with genuine scientific and honorable commercial interests, and it is important to note that this includes in-country scientists as well, a fact that is particularly relevant for developing countries where in-country resources tend to be thinly spread, and where collaboration with external scientific/ academic institutions has been used as a means of addressing such constraints. Failure to clarify a country's policy on access to genetic resources and benefit sharing may thus undermine the resources available for continued research on biodiversity, with serious longterm repercussions for conservation planning. As such, any consideration of access in MAB Reserves should also operate within a national framework that could perhaps include specific provisions that apply to access from MAB Reserves for the purpose of supporting these Reserves' objectives.

The fundamental question remains whether the use of biodiversity in bioprospecting can amount to a sustained strategy for assisting both the CBD and 
the MAB Reserves to link biodiversity conservation with development. Over a decade on from the signing of the $\mathrm{CBD}$, experience suggests that the instances where commercial applications materialize from the use of genetic resources may be less frequent than expected some years back.

Where bioprospecting agreements do materialize, the uncertainties attached to end-of-line payments suggest that countries focus on up-front financial and other more tangible non-monetary capacity building benefits. Particularly beneficial in the context of MAB Reserve activities would be that joint in-country research and development take place that involves local scientific institutions which may benefit from knowledge gained and possibly the transfer of technology.

The sharing of a significant percentage of biodiversity particularly amongst the countries of South Asia (an estimated 40\% between Sri Lanka and India for example) also highlights the need for the setting of a common approach or standards at the regional level. This might include avoiding competition and undercutting between countries in the same region, the facilitation of access through practical and harmonised policies and procedures on access and benefit-sharing, and the mobilization of capacities for joint research that ensures that expertise and benefits remain within the region and facilitates cross-border conservation and sustainableuse programmes. 